D.E.L.T.A., Vol. 15, N. ${ }^{\circ}$ EsPECIAL, 1999 (23-50)

\title{
O Português Brasileiro e as Controvérsias da Fonética Atual: Pelo Aperfeiçoamento da Fonologia Articulatória
}

(Implications of Brazilian Portuguese Data for Current Controversies in Phonetics: Towards Sharpening Articulatory Phonology)

Eleonora Cavalcante Albano (Laboratório de Fonética Acústica e Psicolingüística Experimental - LAFAPE - UNICAMP)

ABSTRACT: The paper examines the recent trends of phonetic studies in Brazil, a productive area which analyses Brazilian-Portuguese data and contributes to phonetic theory. The central question discussed in the approach is the relationship between Phonetic and Phonology. (AE)

KEY WORDS: Phonetics, Phonology, Brazilian Portuguese, Articulatory Gestures, Articulatory Phonology.

Palavas-chave: Fonética, Fonologia, Português Brasileiro, Gestos articulatórios, Fonologia articulatória.

O campo potencial dos estudos fonéticos no Brasil é examinado do ponto de vista da sua implantação recente e da fecundidade dos dados do português brasileiro para iluminar questões da teoria fonética. A questão tomada como central é a da comensurabilidade entre a Fonética e a Fonologia, colocada pela primeira vez de forma objetivável pela Fonologia Articulatória. Numa revisão crítica do programa desse modelo, constata-se: (a) que os seus princípios gerais são perfeitamente adequados para dar conta de muitos processos fônicos pós-lexicais do português brasileiro que a análise fonética revela serem gradientes, contrariando a visão categórica da tradição fonológica contemporânea; (b) que os parâmetros utilizados pelo modelo para representar as vogais são inadequados para a expressão de processos gradientes assim como para a expressão de processos categóricos, o que sugere que algumas das objeções levantadas contra ele na literatura podem ser superadas através de uma revisão dos seus descritores vocálicos. A conclusão oferece perspectivas para a implementação dessa revisão, apontando a relevância de alguns dados do português brasileiro para testar as hipóteses envolvidas.

\section{Introdução}


A história da Fonética como disciplina experimental no Brasil é bastante recente. Isso acontece porque, até o fim da década de 80, o País não oferecia condições mínimas para a instalação e manutenção de um laboratório. As versões analógicas de aparelhos tais como o espectrógrafo, indispensável ao estudo da Fonética Acústica, e o palatógrafo, tão importante para o estudo da Fonética Articulatória, eram extremamente caras e requeriam cuidados técnicos especializados, condições inviáveis para a Universidade, única instituição brasileira a acolher os que se formavam na área. Foi apenas com a informatização da aparelhagem envolvida, diminuindo custos e facilitando a assistência técnica, que os poucos foneticistas do País - todos formados no exterior começaram a substituir as viagens freqüentes por tentativas de criar ambientes de pesquisa em seus próprios departamentos. A primeira metade da década de 90 assistiu a um grande crescimento da área: uma vez formados aqui os primeiros mestres e doutores, a disciplina começou a difundir-se para além das suas fronteiras acadêmicas e geográficas iniciais ${ }^{1}$.

Tanto quanto eu saiba, há apenas cinco laboratórios de Fonética no Brasil, todos de instalação mais ou menos recente e dedicados primariamente à Fonética Acústica. Dois se encontram na Universidade Estadual de Campinas: o Laboratório de Fonética Acústica e Psicolinguística Experimental - LAFAPE -, do Instituto de Estudos da Linguagem, e o Laboratório de Fonética Forense, do Departamento de Medicina Legal da Faculdade de Ciências Médicas. Os demais encontram-se na Universidade Federal do Rio de Janeiro, na Universidade Federal de Minas Gerais e na Universidade Federal de Santa Catarina. A produção desses grupos, geralmente compostos de um foneticista, eventuais colaboradores de áreas afins e alunos de graduação e pós-graduação, tem sido divulgada mais sob forma de dissertações, teses, comunicações a congressos e relatórios a agências de fomento do que em publicações mais definitivas tais como artigos ou livros.

Haveria, então, como pintar um panorama coerente da Fonética Experimental - mesmo Acústica - no Brasil, em sua existência de menos de uma década? No meu entender, não. Implantar um laboratório exige tamanho investimento de tempo e esforço que os foneticistas brasileiros ainda não

\footnotetext{
${ }^{1}$ Dois exemplos notáveis são: (a) Ivone Panhoca Levy (1993) "Uma outra face da nau dos insensatos: a dificuldade de vozear obstruintes em crianças de idade escolar", tese de doutorado, LAFAPE-IEL-UNICAMP, que estendeu a Fonética Acústica ao estudo das patologias da fala; e (b) Ricardo Molina de Figueiredo (1994) "Identificação de falantes: aspectos teóricos e metodológicos", tese de doutorado, LAFAPE-IEL-UNICAMP, que estendeu a Fonética Acústica às aplicações forenses.
} 
tiveram ocasião de se reunir, trocar experiências, sondar afinidades e traçar metas comuns. Seria prematuro, no momento, tentar depreender direções que justificassem um rótulo tal como "Fonética Brasileira", com base em dados dispersos sobre a produção dos laboratórios mencionados. O que se pode dizer é que, embora não tendo ainda uma Fonética, o Brasil já tem um número razoável de bons foneticistas - todos empenhados em resgatar o prejuízo causado pela privação material das décadas de 70 e 80.

Como esse resgate pode fazer-se de muitos pontos-de-vista, vou tomar a minha contribuição a este volume como oportunidade para iniciar a sua discussão. Delinearei a seguir a minha própria visão de como devemos enfrentar a tarefa de implantar uma tradição de estudos fonéticos no Brasil, à luz de alguns resultados já disponíveis no LAFAPE. Com isso não quero diminuir a importância do que se faz em outros centros. Quero, antes, convidar os colegas coordenadores dos demais laboratórios a exporem também as suas perspectivas, dando início a um diálogo que os nossos múltiplos encargos têm adiado.

O leitor que espera encontrar aqui muitas informações sobre a pronúncia do português brasileiro (doravante $\mathrm{PB}$ ) certamente ficará decepcionado. É que a Fonética a que me filio não é descritiva, isto é, não constitui instrumento para nenhuma outra área da Lingüística, mas tem suas próprias teorias e métodos, cujo teste e aperfeiçoamento constituem fins em si mesmos. Assim, não vou mostrar como a Fonética poderia iluminar questões sobre a descrição do PB e sim como o PB pode iluminar questões sobre a teoria fonética.

\section{O vigor atual da fonética teórica}

Dos 598 títulos de comunicações apresentadas ao XIII Congresso Internacional de Ciências Fonéticas, realizado em Estocolmo em 1995, menos de $20 \%$ mencionam línguas específicas (Elenius e Branderud, 1995). Isso não quer dizer que a pesquisa fonética esteja alheia à variedade das línguas do mundo, mas que essa variedade vem cada vez mais sendo concebida como manifestação de princípios fonéticos universais.

A preocupação com universais fonéticos manifestou-se também, nesse congresso, no número de trabalhos que propunham modelos de produção ou percepção de aspectos vários da fala. De modelos específicos do funcionamento de algum articulador a modelos gerais da organização dos sistemas fonéticos, o plenário testemunhou uma adesão majoritária à visão, liderada por autores tais como Stevens (1981), Ohala (1995), Kohler (1995) e 
Lindblom (1995), da Fonética como uma ciência sobretudo explicativa.

Dentre tudo que cabe aos foneticistas explicar, destaca-se o processo de produção, por seu acesso mais fácil à observação e pelo papel que lhe atribuem alguns autores no próprio processo de percepção. Muito do esforço da Fonética contemporânea vem, pois, concentrando-se na tentativa de explicar a dinâmica do trato vocal na produção dos sons de fala. É com as teorias que abordam essa problemática que o restante deste trabalho vai dialogar.

Pretendo mostrar que a pesquisa feita no Brasil pode contribuir para o avanço da teoria fonética, embora de maneira ainda um pouco limitada. Dada a complexidade matemática dos atuais modelos de produção de fala, dificilmente poderíamos, com os nossos atuais recursos materiais e humanos, propor-lhes alternativas acabadas. Podemos, entretanto, reunir dados que os interroguem e até desafiem. Como veremos, os processos fônicos pós-lexicais do PB oferecem uma excelente oportunidade para discutir os modelos fonéticos dinâmicos, que hoje encabeçam a pauta do debate sobre a fronteira entre a Fonética e a Fonologia.

Participar das discussões de ponta no papel de interlocutores e críticos já é bastante para uma comunidade ainda incipiente. Exercícios desse tipo talvez ajudem a atrair e formar a massa crítica necessária para que um dia exerçamos também o papel de proponentes.

\section{Uma controvérsia atual: a fonética e a fonologia são comensuráveis?}

Os modelos de produção de fala só focalizam hoje o movimento de articuladores específicos quando estão investigando as suas bases físicas ou fisiólogicas. O que se modela nos estudos de dinâmica é geralmente uma ação (tal como protruir os lábios) em que estão envolvidos vários articuladores (no caso, o lábio superior, o lábio inferior e a mandíbula). Essas ações são em geral denominadas gestos articulatórios e podem ser vistas como entidades fonéticas que realizam entidades lingüísticas ou como entidades lingüísticas em si mesmas.

O modelo que advoga o gesto articulatório como unidade de análise lingüística é conhecido como Fonologia Articulatória - doravante FAR (Browman e Goldstein, 1985, 1986, 1990a e b, 1992). Ele tem em comum com outros modelos fonéticos dinâmicos (e.g., Kröger, 1993; Fujimura, 1996) o fato de ver o gesto como uma oscilação que faz as trajetórias de vários articuladores concorrerem coesamente para um mesmo fim. É, entretanto, mais ambicioso 
que os outros ao afirmar que essa oscilação, que tem uma duração intrínseca especificada pelos parâmetros de um sistema dinâmico ${ }^{2}$, faz parte da estrutura lingüística.

Como já foi exposto na comunicação do grupo de Fonética do LAFAPE ao último Seminário do Grupo de Estudos Lingüísticos do Estado de São Paulo - GEL 97 - (Albano et al.,1998), a FAR tem bastante sucesso em explicar processos fônicos da fala rápida, tais como assimilações, enfraquecimentos e apagamentos de segmentos. Ao invés de postular regras que alterem a identidade daqueles, ela altera apenas as relações entre eles: os gestos podem reduzir a sua magnitude e/ou aumentar a sua sobreposição, de tal forma que os seus resultados acústicos desapareçam ou soem alterados. Uma vantagem dessa abordagem sobre as descrições mais tradicionais dos mesmos fenômenos é que ela é capaz de expressar gradientes finos ou mesmo contínuos físicos. Por exemplo, se um segmento desaparece em alguns casos e em outros deixa um pequeno rastro no sinal acústico, isso pode ser visto como uma questão de maior ou menor sobreposição dos gestos envolvidos.

Não resta dúvida de que a FAR revelou a natureza dinâmica de muitos processos fônicos que se concebiam antes como simbólicos. No entanto, a sua pretensão a estabelecer-se como modelo fonológico tem encontrado muitas resistências. Muitos (e.g., Clements, 1992) duvidam que um esquema apto a representar gradientes tão próximos do nível físico possa também representar distinções categóricas abstratas.

Zsiga (1997) recentemente apresentou dados empíricos a favor da posição cética nessa controvérsia. Mostrando que, na língua Igbo, processos lexicais de harmonia vocálica promovem uma transformação categórica de [e] em [a4], ao mesmo tempo que processos pós-lexicais de sândi externo promovem uma assimilação gradiente entre duas vogais adjacentes quaisquer, a autora argumenta que uma representação em gestos só é adequada para captar os segundos e propõe uma representação baseada nos traços [+-alto], [+-

${ }^{2} \mathrm{O}$ gesto articulatório é entendido como uma oscilação que afeta simultaneamente o curso temporal de vários parâmetros articulatórios, denominados variáveis do trato, os quais determinam, por sua vez, as trajetórias dos articuladores. Essa oscilação é modelável por um sistema massa-mola que especifica uma trajetória amortecida através de uma equação com os seguintes parâmetros: massa do objeto; amortecimento do sistema; rigidez e comprimento de repouso da mola; deslocamento, velocidade e aceleração instantâneos do objeto. A duração do gesto depende da maior ou menor rigidez da mola: quanto menor a rigidez, maior a duração. A magnitude do gesto depende da diferença entre o comprimento de repouso da mola e a posição inicial do objeto: quanto menor a diferença, menor a magnitude. 
arredondado] e [+-ATR] para captar os primeiros.

A versão atual da FAR tem, de fato, dificuldade de tratar a alternância [e,a] porque representa as distinções vocálicas em termos de graus e lugares de constrição. Sob esse prisma, o [e] e o [a] são pouco relacionados, pois o primeiro tem uma constrição palatal moderada, enquanto o segundo tem uma constrição faríngea estreita. Daí inferir, porém, que o processo não seja passível de representação gestual é negar que se possa rever o modelo substituindo os parâmetros atuais por outros mais adequados.

Como veremos abaixo, o fato de o modelo poder representar processos gradientes traz muitas vantagens. Se ele se revela, ao mesmo tempo, inadequado para expressar distinções categóricas, não se pode apressadamente concluir que isso indica a existência de um fosso entre a Fonética e a Fonologia. Devese, ao contrário, perguntar se as dimensões envolvidas na passagem de um nível a outro estão ou não sendo corretamente representadas na versão corrente do modelo.

A análise fonético-acústica do PB traz pistas importantes para a elucidação desse problema. Se, de um lado, há evidência de que muitos processos fonológicos tradicionalmente vistos como categóricos são, na verdade, gradientes, há, de outro, uma forte sugestão de que os gradientes envolvidos na redução das vogais átonas se expressem melhor pela tradicional dimensão da altura vocálica do que pelos graus de constrição propostos pela FAR. Ora, a necessidade de exprimir uma categoria como vogal não-alta é o que está em jogo quando se considera alternâncias lexicais tais como a do [e, a 4 ] no Igbo.

$\mathrm{O}$ meu argumento a favor de perseguir a comensurabilidade entre a Fonética e a Fonologia através de uma crítica construtiva à FAR divide-se em duas partes. Primeiro, mostrarei que um modelo gestual nos seus moldes gerais é, de fato, necessário para dar conta de processos fonológicos até agora vistos como categóricos no $\mathrm{PB}$, a saber: a nasalização, a palatalização, o vozeamento e a elisão. Depois mostrarei que o fenômeno da elevação das vogais átonas, cuja gradiência é menos surpreendente, é problemático para qualquer modelo que não contemple a altura como parâmetro de descrição vocálica. Com isso argumentarei que as modificações requeridas para que o modelo refine a sua capacidade de exprimir processos gradientes apontam na mesma direção que as necessárias para que consiga também exprimir processos categóricos. 
A implementação dessas modificações em termos dinâmicos está, por outro lado, fora da minha competência. Mas acredito que, na medida em que o que está em jogo é a explicitação da distinção entre gestos consonantais e vocálicos, os numerosos processos de vocalização de consoantes encontrados no PB venham a constituir um forte incentivo para que foneticistas brasileiros oriundos da Física ou da Engenharia enveredem pelo campo do modelamento dinâmico, criando ferramentas que permitam operacionalizar e testar hipóteses como as que levanto na conclusão.

3. Evidência para um modelo gestual: a gradiência de certos processos fônicos do PB

Na já mencionada comunicação do grupo de Fonética do LAFAPE ao GEL 97 (Albano et al., 1998), demonstramos a inviabilidade de representar processos fônicos gradientes via escalas discretas, tal como sugerido por Chomsky e Halle (1968) e implicitamente aceito por grande parte da literatura fonológica até hoje. O nosso principal argumento é que muitos desses processos envolvem gradientes de duração condicionados por múltiplos fatores, de tal forma que o número de graus da suposta escala discreta se torna arbitrário e imprevisível. Em contrapartida, a existência maciça de processos gradientes no $\mathrm{PB}$ e o seu caráter inegavelmente lingüístico (isto é, não-mecânico) levam à necessidade de um mecanismo motivado de geração de contínuos físicos, que, numa primeira aproximação, pode ser visto como o componente dinâmico da FAR.

Mostrarei a seguir que alguns processos comumente vistos como categóricos no PB são gradientes ou têm versões gradientes que envolvem variações de parâmetros fonéticos só representáveis num modelo capaz de gerar contínuos físicos como a FAR.

\subsection{Nasalização}

Todos os fonólogos que aceitam a análise mattosiana (Câmara Jr., 1969) - isto é, VN - das chamadas vogais nasais do português postulam uma regra de nasalização e uma regra de apagamento da nasal para explicar a forte nasalização da vogal e a freqüente ausência de consoante nasal seguinte. Por outro lado, alguns fonólogos notam a presença de uma consoante nasal, dita intrusiva, entre a vogal nasal e uma consoante de início de sílaba seguinte, com a qual é sempre homorgânica. A descrição tradicional desses fatos pode ser assim resumida: 
(1) (a) V $\rightarrow$ vâ /_N

(b) $\mathrm{N} \rightarrow 0 /$ vâ

(c) $0 \rightarrow \mathrm{N} /$ vâ _. $\mathrm{C}$

Dados fonético-acústicos analisados por Sousa (1994) sugerem que os fatos são, na realidade, mais complexos. Em primeiro lugar, a vogal não se nasaliza completamente de imediato, mas apresenta uma configuração de formantes próxima de vogal oral no início e típica de vogal nasal no final. Em segundo lugar, as regras (b) e (c) não são independentes, mas se aplicam de forma gradiente e complementar: se a vogal é longa, a nasal "intrusiva" - ou, em termos fonético-acústicos, o murmúrio nasal - pode não aparecer, mas, quando aparece, tem uma duração inversamente proporcional à da vogal.

A Figura 1 mostra o espectro de uma vogal oral comparado ao início, ao meio e ao fim - porção onde emerge o murmúrio nasal - de uma vogal nasal, indicando o caráter gradiente da nasalização.

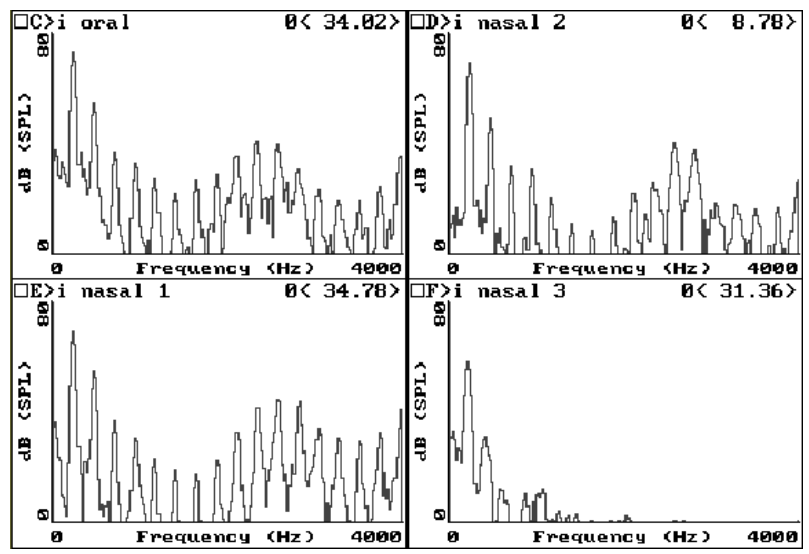

Figura1-Espectro FFT $^{3}$ de: (c) [iâ]; (e) o início de [iâ], (d) o meio de [iâ] e o (f) o f im de [îa]

\footnotetext{
${ }^{3}$ Abreviatura para Fast Fourier Transform, algoritmo que realiza, com grande rapidez, uma análise discreta de Fourier em microcomputadores.
} 
A Figura 2 mostra o gráfico de dispersão da duração do murmúrio nasal em função duração da vogal nasal para os dados de Sousa (op. cit.). A correlação de $-0,7$ ésignificativa, com $p<0,0001$

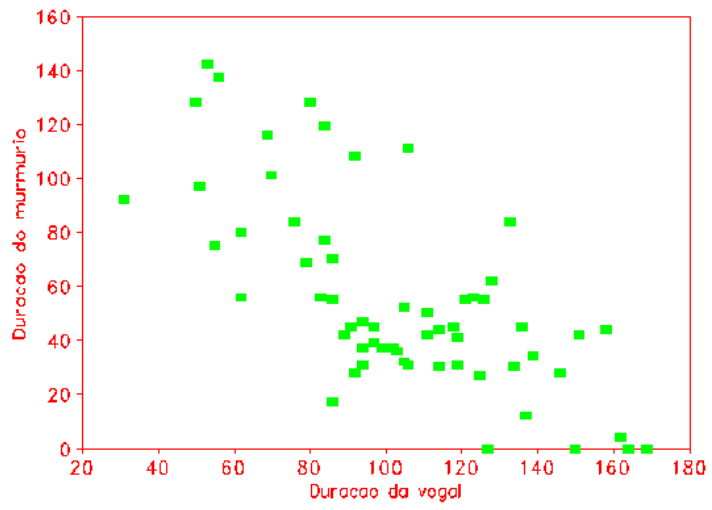

Figura 2 - Duração do murmúrio nasal que acompanha as vogais nasais em função da duração dessas, ambas em ms

Por serem quantitativos, esses dados não se acomodam nos modelos fonológicos simbólicos - nem mesmo nas mais sofisticadas versões da Fonologia Autossegmental. Essa, por exemplo, não é capaz de expressar a complementaridade de duração entre a vogal e a nasal "intrusiva", embora seja capaz de representar a segunda como subsegmental.

Em contraste, a descrição da FAR é direta e intuitivamente satisfatória. Ela postula um gesto de abertura vélica que começa depois do início do gesto vocálico e termina depois do fim desse. A presença ou não de nasal "intrusiva" depende da maior ou menor sobreposição entre o gesto consonantal seguinte e os gestos vocálico e vélico, que não é especificada no léxico, podendo variar de acordo com o contexto prosódico, segmental ou mesmo pragmático. A Figura 3 formaliza essa análise nos termos das pautas (scores) gestuais utilizadas pela FAR. As camadas (tiers) correspondem a variáveis do trato - os 
parâmetros que são afetados pelas oscilações que especificam os gestos. Assim, abertura vélica (AV) é a variável do trato que especifica o gesto de nasalização. Grau e lugar de constrição do corpo da língua (respectivamente, GCCL e LCCL) são as variáveis do trato que especificam o gesto vocálico. Finalmente, abertura labial (AL) é a variável do trato que especifica o gesto consonantal seguinte (nesta ilustração, uma labial). O comprimento das barras é uma aproximação gráfica das durações intrínsecas que são especificadas no componente dinâmico da FAR (V. nota 2).

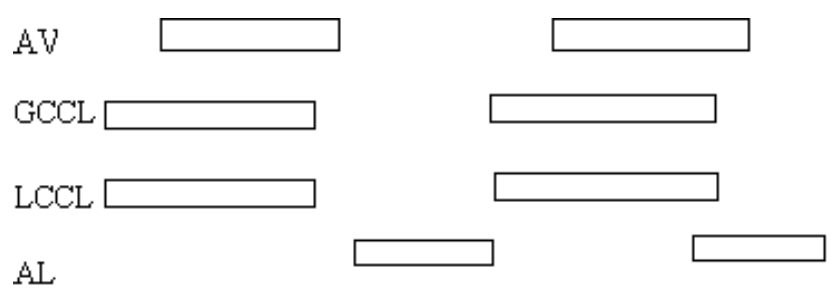

Figura 3 - Pautas gestuais para a ocorrência de nasalização sem (esquerda) e com (direita) murmúrio nasal em PB

O interessante da representação da Figura 3 é que ela prevê exatamente a correlação negativa alta, mas inferior a 1 , encontrada entre a duração do murmúrio e a duração da vogal. Note-se que é possível o caso em que o gesto consonantal seguinte se sobrepõe ao gesto nasal, mas não ao gesto vocálico. Esse caso poderia explicar os $30 \%$ dos dados em que a duração do murmúrio não é previsível a partir da duração da vogal.

O sucesso da FAR, face ao fracasso dos modelos fonológicos tradicionais, no trato de processos como este coloca-nos a seguinte questão: admiti-la como meio de modelar processos fônicos de línguas específicas é admiti-la como modelo fonológico?

Responder não - isto é, só admitir a FAR como modelo de implementação fonética - implica, como demonstrará o resto desta seção, delegar quase toda a fonologia pós-lexical ao componente fonético. Por outro lado, responder sim - isto é, admitir a FAR como modelo de representação lexical - implica pensar seriamente a questão de como reduzir as suas dimensões contínuas a escalas discretas, capazes de exprimir as oposições distintivas e alternâncias categóricas típicas da fonologia lexical.

Vejamos primeiro por que é preciso reconhecer ainda outros processos 
gradientes na fonologia pós-lexical do PB.

\subsection{Palatalização das oclusivas coronais diante de /i/}

Em vários dialetos brasileiros, existe um processo de palatalização das oclusivas coronais diante de /i/ que resulta numa africada alveopalatal. Eis a sua descrição tradicional:

$$
\text { (2) } / \mathrm{t}, \mathrm{d} / \rightarrow[\mathrm{tS}, \mathrm{dz}] / \_\mathrm{i}
$$

Esse processo tem interesse dialetológico e sociolingüístico, pois a sua aplicação diferencia regiões e faixas etárias. Auditivamente, pode-se falar de grupos africadores (e. g., os cariocas de qualquer idade) e grupos nãoafricadores (e. g., os paulistanos de mais de 50 anos).

Um exame mais atento de sujeitos não-africadores mostra, entretanto, uma situação mais delicada. Mesmo aqueles que vêem o "chiado" como característica alheia à sua fala, não conseguem deixar de palatalizar o /t/ e, curiosamente, também o/s/, em palavras terminadas em "ístico/a" tais como lingüística, místico, dístico, eucarístico. A Figura 4 mostra espectrogramas de um sujeito não-palatalizador pronunciando tias e lingüística. Note-se que lingüística apresenta palatalização de /s/ e africação de /t/, evidenciadas por ruídos fricativos cujos picos de energia se iniciam numa freqüência bem mais baixa do que o do /s/ de tias.

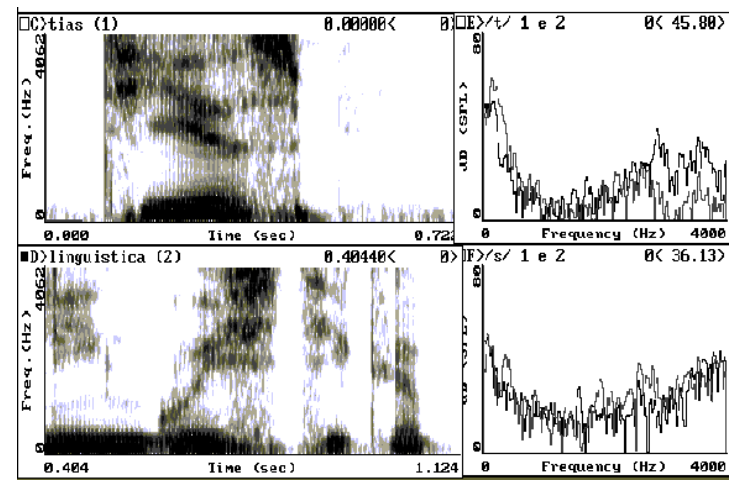

Figura 4 - Pronúncias não-palatalizadas (c: tias) e palatalizadas (d: lingüística) $\mathrm{de} / \mathrm{t} / \mathrm{e} / \mathrm{s} /$ por um mesmo sujeito de grupo dialetal não-palatalizador. Comparar espectros (e; f) 
Este parece ser um caso típico de mudança lingüística em curso: sujeitos relativamente conservadores só apresentam o processo em ambientes muito propícios. Uma outra indicação de que a mudança está em curso em grupos não-africadores é a diferença entre o /t/ da pré-tônica e o /t/ da tônica da palavra titia em sujeitos da faixa etária mais jovem da cidade de Jundiaí, no Estado de São Paulo, onde a palatalização parece estar apenas começando a se difundir. Na Figura 5, o ruído que segue o silêncio do segundo /t/ não deve ter sido gerado apenas pela liberação da oclusão, pois se prolonga consideravelmente e tem alta concentração de energia na região de $2500 \mathrm{~Hz}$. Note-se que é a vogal tônica, normalmente mais longa que a pré-tônica, que propicia a fricção:

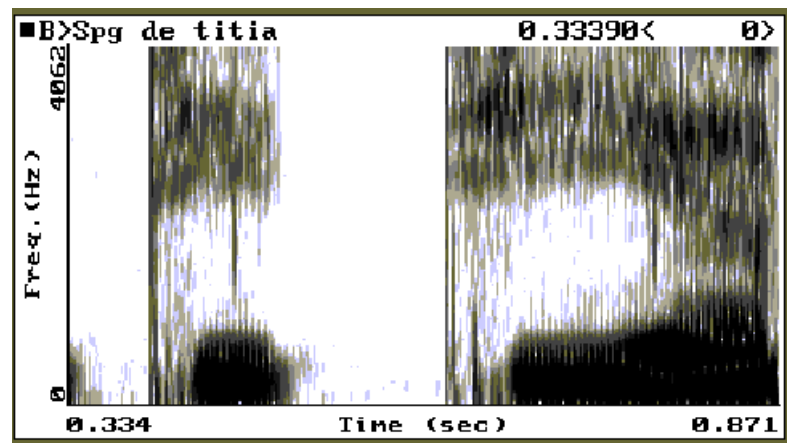

Figura 5 - Exemplos de /t/ com graus de palatalização distintos em um mesmo sujeito

Embora sendo apenas preliminares e não fazendo parte de um estudo sociolingüístico sistemático, esses dados sugerem que a palatalização não se difunde de maneira categórica e sim gradiente. Ora, o único modelo capaz de entendê-la como um contínuo que vai de uma ligeira coloração de [i] à africação é a FAR. Ela afirmaria que a sobreposição entre os gestos do /t/ e do /i/ pode aumentar até produzir efeitos audíveis de fricção. A sua contribuição é particularmente valiosa para racionalizar a dupla palatalização das palavras em 'ístico" em falantes não-africadores.

A Figura 6 mostra a pauta gestual de [íStSi]. A hipótese de que, nos falantes em questão, os dois gestos vocálicos se aproximem muito (devido, talvez, à atonicidade do segundo /i/) explica por que eles se sobrepõem 
completamente aos gestos consonantais, tornando impossível evitar a palatalização. Além das variáveis do trato GCCL e LCCL (grau e lugar de constrição do corpo da língua), responsáveis pela especificação das vogais, comparecem as variáveis do trato: grau e lugar de constrição da ponta da língua (GCPL e LCPL, respectivamente), responsáveis pela especificação das consoantes coronais.

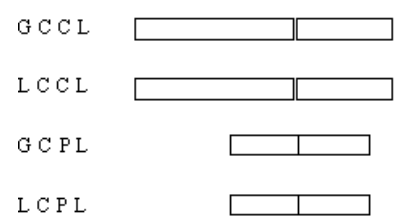

Figura 6 - Pauta gestual de [íStSi] para sujeitos normalmente não-africadores

Não seria parcimonioso postular dois mecanismos distintos para explicar a palatalização gradiente dos dialetos em mudança e a palatalização categórica dos dialetos já africadores. Assim, mais uma vez, a FAR sai-se melhor que os modelos fonológicos tradicionais. À sua luz, o grau de sobreposição entre os gestos da oclusiva e da vogal é apenas maior e mais fixo nos dialetos africadores que nos não-africadores.

\subsection{Vozeamento de/s/ em final de sílaba}

Um fato muito conhecido sobre o português em geral é a concordância de voz do /s/ de final de sílaba com o ambiente seguinte. Precedendo consoante surda ou pausa, ele é surdo. Precedendo consoante vozeada ou vogal, ele é vozeado. A descrição tradicional desse processo é:

$$
\text { (3) } / \mathrm{s} / \rightarrow[\mathrm{z}] / \text { _ \#) [+vozeado] }
$$

Entretanto, a análise espectrográfica do PB revela uma situação mais complicada. O processo é categórico em posição medial, mas torna-se gradiente em posição final, dependendo da força da fronteira seguinte. Fronteiras fracas propiciam o vozeamento total. Fronteiras fortes inibem-no ou tornam-no parcial.

Ainda não tivemos ocasião, no LAFAPE, de promover um estudo 
experimental dessa questão, pois a montagem do corpus exigiria uma teoria preditiva da força das fronteiras, demandando uma avaliação das opções disponíveis na chamada Fonologia Prosódica, o que é uma tarefa trabalhosa e delicada. Temos, entretanto, observado uma variabilidade da extensão do vozeamento em corpora gravados para outros fins. Isso se aplica inclusive ao ambiente mais propício ao vozeamento, que é a juntura com vogal. Dependendo da força da fronteira, o [z], que costumamos entender como ressilabificado, é apenas parcialmente vozeado.

A Figura 7 compara o /z/ subjacente de "Ouvi-o zurrar" ao [z] derivado de "Ouvi os urros", assim como aos [zz] derivados de duas emissões de "Ouvi-os urrar", uma normal e outra rápida. Na fronteira fraca, a pronúncia normal é vozeada. Já, na fronteira forte, nem mesmo a pronúncia rápida o é inteiramente.

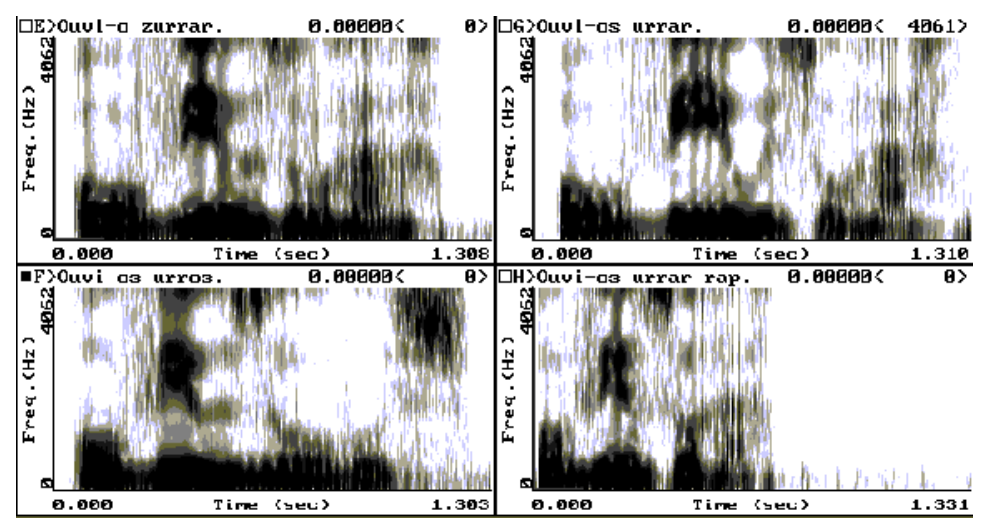

Figura 7 - O /z/ de "Ouvi-o zurrar" (e), comparado ao /s/ totalmente vozeado de "Ouvi os urros" (f) e ao /s/ parcialmente vozeado de "Ouvi-os urrar"(g: fala normal; h: fala rápida)

Como no caso da africação, não seria parcimonioso usar mecanismos diferentes para tratar o vozeamento categórico das fronteiras fracas (ou de posições interiores a morfemas) e o vozeamento gradiente das fronteiras fortes. 
A FAR fornece uma maneira bastante direta de unificar as duas versões do processo. Em ambas, o gesto de abertura glotal diminui enquanto o gesto de constrição oral se sobrepõe aos gestos vocálicos adjacentes. Porém, no vozeamento total, a diminuição e a sobreposição são mais pronunciadas. A aproximação dos dois gestos vocálicos é, provavelmente, como no exemplo anterior, o desencadeador do processo. Note-se aqui a presença da variável do trato abertura glotal (AG), que especifica a ausência de vozeamento. $\mathrm{O}$ vozeamento das vogais não foi representado por ser considerado padrão (default).

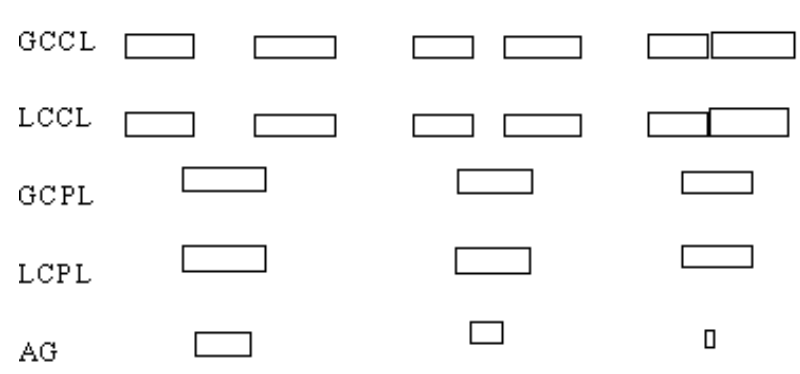

Figura 8 - Pautas gestuais para [osu], [oz¥u] e [ozu]

Embora a Fonologia Autossegmental seja capaz de representar - através de um contorno do traço vozeado - um único grau de vozeamento parcial, a explicação da FAR parece mais atraente porque prevê aí um gradiente mais fino. Se ele é, de fato, necessário é uma questão empírica que só poderá ser resolvida quando tivermos um corpus bem controlado quanto à força das fronteiras envolvidas.

3.4 Elisão de /a/ átono em juntura com vogal átona

Outro processo até agora visto como categórico pelos estudiosos do PB é a elisão de /a/ átono em juntura com outra vogal átona. Em termos tradicionais:

(4) /a/[-acento] $\rightarrow 0 /$ \# V[-acento]

Na comunicação ao GEL já citada (Albano et al.,1998), demonstrei que, em alguns casos que a transcrição de outiva trata como elisão, a vogal 
supostamente elidida deixa um rastro claro no sinal acústico. Assim, a pronúncia de "cara idoso" tem, pelo menos, três versões: uma com encontro vocálico nítido, uma muito próxima de "caridoso" e outra intermediária, onde os valores de F1 e F2 logo após a liberação do [R] evidenciam um breve resquício de [a]. Reproduzo aqui os espectros que mostram essa gradação

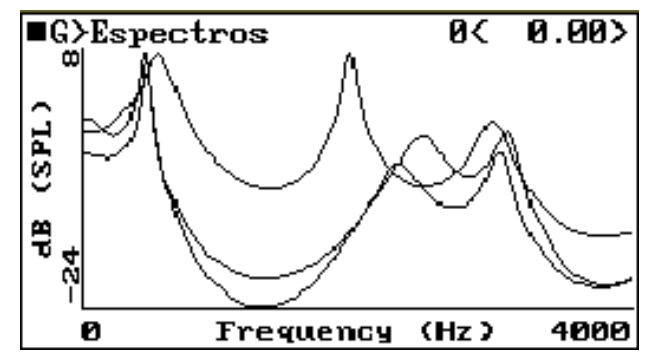

Figura 9 - Espectros LPC 20 ms após a liberação do [R] em três pronúncias (lenta, moderada e rápida) de "cara idoso"

Essa gradiência é impossível de representar na Fonologia Autossegmental, pois o único recurso disponível, que é associar /i/ à casa segmental já associada a /a/, criando um contorno, preveria uma manutenção da duração com um aumento do [i] concomitante à diminuição do /a/, o que não ocorre. Em contraste, a FAR prevê que o gesto do /a/ pode diminuir e ocultar-se sob o gesto do /i/, o que explica os dados observados. Assim, as pautas segmentais para os três casos seriam como na Figura 10.

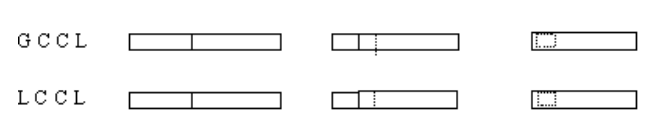

Figura 10 - Pautas gestuais para o encontro vocálico de "cara idoso" sob três taxas de elocução (lenta, moderada e rápida)

A interpretação gradiente da elisão ganha ainda mais força quando se considera que ela interage com o processo de palatalização discutido acima. Nos grupos africadores, a palatalização geralmente não se aplica quando o/i/ se torna adjacente a/t,d/ devido à elisão. A Figura 11 mostra o espectrograma

\footnotetext{
${ }^{4}$ Espectros obtidos pelo método Linear Predictive Coding (codificação por predição linear), que assume que o trato vocal é um filtro sem perdas.
} 
da expressão "muit' idade" pronunciada por um falante do dialeto carioca, que tem uma africação bem acentuada diante de /i/ subjacente (como em "tinha") ou derivado por elevação (como, e.g., em "t[e/i]atro").

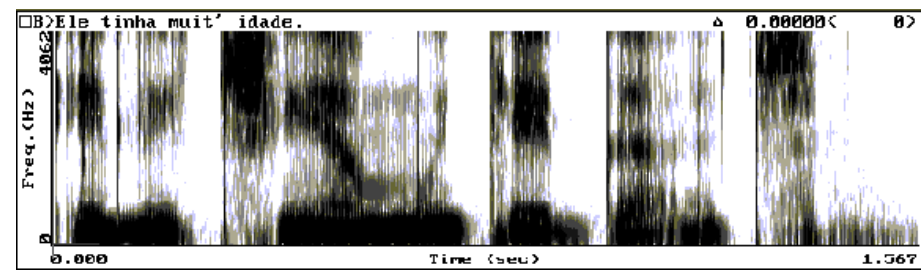

Figura 11 - Ausência de africação em "muit' idade" pronunciada por falante carioca

Os modelos que tratam ambos os processos como categóricos precisam apelar para a ordenação de regras ou de componentes a fim de bloquear a africação de /t,d/ seguido de /i/ por obra da elisão. Embora não sendo tão ad hoc como a ordenação de regras, a ordenação de componentes é implausível neste caso: para que funcionasse, seria necessário fazer da africação um processo lexical, separando-a da elisão, que, por aplicar-se apenas em fronteiras de palavras, é inerentemente pós-lexical. Ora, isso implicaria que todas as elevações opcionais de /e/ que alimentam a africação fossem lexicais (e. g. t[e/ i]atro, t[e/i]oria). É, no entanto, incoerente tratar como lexicais processos opcionais que dependam de estilo e velocidade de fala, fatores que costumam condicionar processos pós-lexicais.

Em contrapartida, na análise da FAR é o gesto oculto do /a/ que impede o contato do/t/ com o/i/ na pauta gestual de "muit' idade". Na Figura 12, esse gesto é representado pela barra pontilhada:

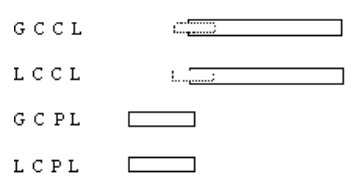

Figura Figura 12 - Pauta gestual de "muit' idade" mostrando bloqueio da africação de /t/ pela presença de um /a/ oculto 
Os quatro exemplos examinados devem ter bastado para mostrar que um tratamento sério dos padrões fônicos do PB passa por uma tentativa de compreender a relação entre processos gradientes e seus análogos categóricos. Modelos que estabelecem um fosso entre a Fonética e a Fonologia estão fadados a tratar versões apenas distintas do mesmo processo como radicalmente divorciadas. A FAR, por sua vez, realiza a proeza de unificar fenômenos aparentemente distintos, mas o faz deixando em aberto o número e os tipos de processos fônicos possíveis, ao supor que a diferença entre o discreto e o contínuo está apenas no número de graus de liberdade.

Descartá-la, entretanto, pelo seu excessivo poder gerativo é jogar fora o bebê com a água do banho. O que faz sentido, diante de fatos como os expostos acima, é investigar se os parâmetros exigidos para a descrição de processos gradientes são os mesmos e podem ser racionalmente reduzidos para a descrição de processos categóricos. A discussão que segue é uma primeira tentativa nessa direção.

\section{O Vocalismo átono do PB e a representação das vogais no FAR}

As vogais do PB constituem um fértil terreno para o estudo da relação entre processos categóricos e gradientes. Elas têm pronúncias variáveis conforme a posição relativa ao acento e há razões para crer que essa variabilidade resulta dos efeitos somados de processos categóricos sensíveis à posição do acento e ao contexto segmental e de processos gradientes sensíveis ao estilo e à taxa de elocução.

Do lado categórico, há processos de neutralização das distinções de altura das vogais não-baixas nas posições pré-tônica e pós-tônica e em ambiente nasal. Do lado gradiente, há processos de redução de todas as vogais nas posições átonas, especialmente a pós-tônica (sobre a gradiência da redução, ver 4.2). Embora seja difícil separar os efeitos de processos que se aplicam em ambientes semelhantes, o fato de a redução afetar também o /a/, vogal que não está sujeita à neutralização, revela a sua existência independente.

Intuitivamente, a neutralização e a redução parecem ser manifestações da mesma tendência do PB a compactar o espaço vocálico nas posições átonas. Essa tendência é, entretanto, impossível de captar unificadamente nos modelos fonológicos tradicionais, que, ao conceber os traços como binários, privativos ou mesmo escalares, limitam severamente o número de distinções vocálicas possíveis, inviabilizado a expressão dos múltiplos graus de compressão do 
espaço vocálico envolvidos na redução.

Como se sai a FAR nessa tarefa? Se, por um lado, ela possui meios de expressar pequenos deslocamentos no espaço vocálico, por outro, o faz com parâmetros alheios às descrições tradicionais do $\mathrm{PB}$, que costumam entender esses processos como alterações de altura. Seriam, então, a neutralização e a redução descritíveis em termos de graus e lugares de constrição?

Lembremos que a principal divergência do sistema de constrições com relação ao de altura é o tratamento da vogal /a/, especificada naquele com uma constrição faríngea estreita. Um ponto a investigar é, portanto, como /a/ se relaciona com as séries anterior (palatal nos termos da FAR) e posterior (velar nos termos da FAR).

Veremos que a neutralização e demais processos vocálicos categóricos do PB entram em conflito com essa concepção do /a/ como radicalmente distinto das vogais anteriores e posteriores. Isso nos autorizaria, então, a concluir com Zsiga $(1995,1997)$ que a fonologia maneja alturas categóricas, enquanto a fonética maneja constrições gradientes?

Dados preliminares do LAFAPE (Aquino, 1997) sugerem que não. Um modelo como a FAR prevê que a redução afrouxe as constrições de todas as vogais, implicando o abaixamento de [i] e [u] e a elevação de [a]. Aquino encontrou, entretanto, casos de elevação de [i] na posição mais propícia à redução, que é a pós-tônica. Eis um fato que a FAR pode descrever (via aumento ad hoc da constrição), mas não explicar.

Fatos como esse fazem pensar na possibilidade de usar diretamente a altura como descritor vocálico numa versão modificada do componente dinâmico do modelo. Isso teria a vantagem de tornar os processos vocálicos gradientes isomorfos aos seus análogos categóricos, mas criaria, ao mesmo tempo, uma distância muito maior entre as especificações das vogais e das consoantes. Prós e contras desse caminho serão discutidos na conclusão.

\subsection{O papel da altura nos processos vocálicos categóricos do PB}

O fato de o PB ter sete distinções vocálicas na posição tônica, cinco na pré-tônica e três na pós-tônica é bastante conhecido. Uma maneira conveniente de expressá-lo é a análise arquifonêmica de Joaquim Mattoso Câmara Jr. (1969, 1976, 1977), resumida na Figura 13: 


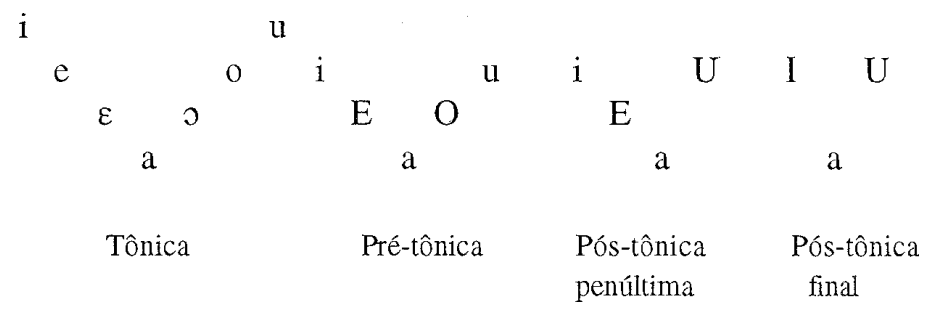

Figura13 - Vogais do PB, conforme a posição do acento, na visão de Mattoso Câmara Jr.

Esse quadro diz (a) que a distinção entre vogais médio-altas e médiobaixas se neutraliza na pré-tônica e (b) que a distinção entre vogais altas, médio-altas e médio-baixas se neutraliza na pós-tônica, sem, entretanto, nada afirmar sobre a direção dessas neutralizações. Isso é conveniente porque há, de fato, uma grande variação dialetal na realização dos arquifonemas resultantes. Assim, por exemplo, /I/ e /U/ tendem a soar como [I] e [U] na maior parte do sudeste e como [e] e [o] em certas regiões do sul. Da mesma forma, em certas regiões do nordeste, a neutralização da pré-tônica não é transparente, pois interage com processos de abaixamento que resultam em $[\mathrm{E}] \mathrm{e}[\bullet]$.

O importante sobre a neutralização é que todos os processos derivacionais e flexionais que implicam um deslocamento do acento podem alimentá-la. Assim, - para exemplificar com fatos do sudeste, que são melhor conhecidos - encontram-se alternâncias tais como b[E]lo/b[e]leza, m[•]ra/ $\mathrm{m}[\mathrm{o}] \mathrm{ramos}$. Independentemente de se o estilo favorece ou não uma pronúncia mais ou menos reduzida, há uma variação categórica de altura da tônica para a pré-tônica.

As descrições tradicionais desse fato simplesmente mencionam o parâmetro altura, seja ele concebido como traço binário ou escalar. A descrição da FAR é, por outro lado, bem mais complicada. Para poder mencionar o parâmetro grau de constrição, ela deve especificar as vogais-alvo como sendo palatais ou velares, a fim de excluir o /a/, que não participa do processo (ou seja, [a] ocorre tanto na tônica como na pré-tônica).

Essa complicação se torna preocupante quando lembramos que o PB tem uma restrição à ocorrência de vogais em ambiente nasal que reduz o inventário das vogais médias ao mesmo tempo que altera o /a/. Assim, 
continuando a adotar a análise $\mathrm{VN}$ das chamadas vogais nasais, temos que diante de /N/ só ocorrem [i], [e], [๕], [o] e [u]. Ora, a descrição tradicional vê aí uma restrição à ocorrência de vogais baixas em ambiente nasal. Já a FAR é obrigada a afirmar que a presença do gesto vélico impede constrições largas nas vogais palatais e velares e constrições estreitas nas vogais faríngeas. Isso, evidentemente, constitui uma grave perda de generalização.

A mesma generalização se perde na formulação das alofonias da póstônica. Um sistema como o do sudeste, que contém [I], [๕] e [U], não pode ser visto como uniformemente resultante de processos de elevação (de /e/, /a/ e / $\mathrm{o} /$, respectivamente).

Problemáticos para a abordagem por constrição são também os processos lexicais de alternância vocálica na conjugação verbal. Formas como $\mathrm{m}[\bullet$ ]ro ou $1[\mathrm{E}]$ vo costumam ser explicadas pela influência da vogal temática subjacente / a/, que abaixaria as vogais médias do radical (mor+a+o, lev+a+o). A FAR não é capaz de expressar essa generalização, visto que uma constrição faríngea estreita não poderia, em princípio, alargar uma constrição palatal ou velar.

Concluímos assim que a FAR se sai mal na descrição dos processos vocálicos categóricos do PB. Esse fracasso não é, entretanto, generalizado, circunscrevendo-se ao aspecto do modelo que especifica as vogais via graus e pontos de constrição.

\subsection{Um caso difícil para a FAR: elevação gradiente de [I] pós-tônico}

Como já foi mencionado, uma boa razão para separar a neutralização da redução é que essa afeta o /a/, vogal que não tem par no inventário tônico do $\mathrm{PB}$, não podendo, portanto, participar de processos de neutralização. Outra razão, igualmente forte, é que a redução - mais diretamente observável no /a/ pós-tônico - é sensível a fatores gradientes tais como estilo, taxa de elocução e força das fronteiras prosódicas.

Em sua contribuição a Albano et al. (1998), Sandra Madureira expôs dados em que o F1 e o F2 de [Æ] pós-tônico variam, na mesma palavra, de acordo com a força das fronteiras prosódicas. Numa fronteira forte (final de enunciado), F1 é mais baixo e F2 é mais alto que numa fronteira fraca (interior a um sintagma nominal), o que evidencia graus distintos de redução, aparentemente proporcionais à força das fronteiras. Isso permite argumentar que a redução é um processo contínuo, já que a força das fronteiras se cruza 
com os demais fatores gradientes mencionados, criando um leque muito amplo de possibilidades.

Que a redução afeta também o /I/ e o/U/ pós-tônicos, sobrepondo-se ao efeito da neutralização, pode-se demonstrar comparando-se a dispersão de F1 e F2 na pós-tônica e na tônica. As Figuras 14 e 15 mostram, respectivamente, o espaço vocálico tônico e pós-tônico para um falante paulistano do PB. Note-se que tanto F1 como F2 apresentam uma maior dispersão na posição pós-tônica.

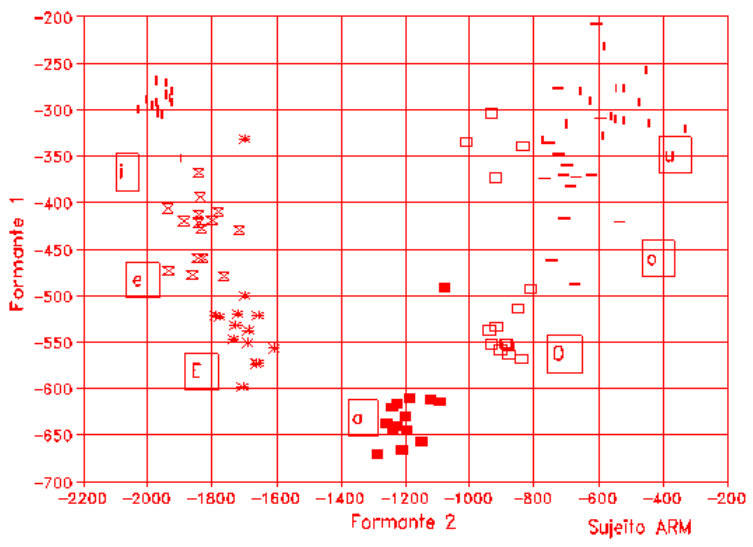

Figura 14 - Espaço vocálico tônico em $\mathrm{Hz}$ para um falante paulistano do PB (Sujeito 1)

Esses dados podem ser resumidos calculando-se o coeficiente de variação (isto é, o desvio padrão como percentagem da média) para F1 e F2 de [i], [a] e [u] tônicos e [I], [⿷] e [U] pós-tônicos. A tabela 1 exibe esses resultados. 


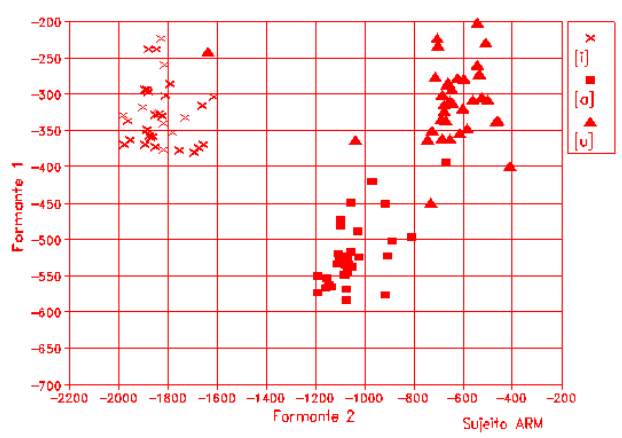

Figura 15 - Espaço vocálico pós-tônico em Hz para o Sujeito 1

\begin{tabular}{|c|c|c|c|c|c|c|}
\hline & Tờnica & Pós-Tồn & Tồnica & Pós-Tờn. & Tồnica & Pós-Tơn \\
\hline & [1] & [I] & [a] & {$[\mathrm{B}]$} & {$[u]$} & {$[6]$} \\
\hline $\mathrm{CV}$ de $\mathrm{Fl}$ & $632 \%$ & $1266 \%$ & 664 & $1039 \%$ & $905 \%$ & $16,45 \%$ \\
\hline $\mathrm{CV}$ de $\mathrm{F}$ & $166 \%$ & $489 \%$ & $268 \%$ & $1213 \%$ & $1916 \%$ & $30,42 \%$ \\
\hline
\end{tabular}

Tabela 1 - Coeficientes de variação para F1 e F2 de [i], [a] e [u] tônicos e [I], [๕] e [U] pós-tônicos do Sujeito 1

É evidente que [I] e [U] não podem ter sido gerados exatamente pelo mesmo mecanismo de produção que [i] e [u], pois isso deixaria inexplicados os diferentes graus de dispersão refletidos nos coeficientes de variação. Assim, além da neutralização da série anterior e posterior, é preciso postular um processo adicional - a redução - que explique por que [I] e [U] se dispersam tanto em torno da média, aproximando-se, com isso, de [๕], vogal para a qual os efeitos da redução não são ambíguos.

Demonstrado o caráter gradiente da redução e sustentada a hipótese da sua existência para todas as vogais pós-tônicas, passemos a considerar como 
se poderia explicá-la. Para tanto, a FAR dispõe de um mecanismo muito conveniente: trata-se da redução da magnitude dos gestos articulatórios. Nas vogais reduzidas, encurta-se a diferença entre a posição inicial da variável do trato envolvida e o comprimento de repouso da mola através da qual se modela o sistema dinâmico. Com isso o gesto perde amplitude e não chega a alcançar o alvo, como no clássico modelo do target undershoot de Lindblom (1963).

A redução da magnitude do gesto articulatório prevê uma centralização das vogais tal como observada na Figura 14, em oposição à Figura 13: tomandose [i], [a] e [u] como referência, F1 aumenta para [I] e [U] e diminui para [E], enquanto $\mathrm{F} 2$ aumenta para [E] e [U] e diminui para [I]. A FAR tem, portanto, bastante sucesso em explicar os dados das vogais pós-tônicas deste sujeito.

Mas esse não é o caso para o sujeito estudado por Aquino (op. cit.). Diferentemente do primeiro, este falante (um recifense com muitos anos de residência em Campinas) não apresenta uma dispersão muito grande dos valores de F1 e F2 das vogais pós-tônicas em torno das respectivas médias, conforme indicado pelos coeficientes de variação da Tabela 2. Pode-se supor, então, que em geral utilize um grau menor de redução, o que é corroborado pelo fato de esses coeficientes não serem muito maiores que os das tônicas correspondentes.

\begin{tabular}{|c|c|c|c|c|c|c|}
\hline & Tồnica & Pós-Tờn & Tỡuica & Pós-Tờn. & Tồtica & Pós-Tờn. \\
\hline & {$[1]$} & [I] & [a] & {$[\mathrm{B}]$} & {$[\mathrm{u}]$} & {$[0]$} \\
\hline $\mathrm{CV} d e \mathrm{Fl}$ & 3.53 & 6.03 & 3.13 & 6.38 & 8.81 & 12.96 \\
\hline $\mathrm{CV}$ de $\mathrm{F}$ & 3.05 & 8.56 & 3.31 & 6.79 & 6.69 & 10.36 \\
\hline
\end{tabular}

Tabela 2 - Coeficientes de variação para F1 e F2 de [i], [a] e [u] tônicos e [I], [๔] e [U] pós-tônicos para um falante recifense (Sujeito 2)

Isso, porém, não explica o achado mais curioso de Aquino, a saber: contrariamente ao esperado (que é a tendência a elevar F1, centralizando a vogal), [I] tem um F1 significativamente inferior ao de [i], sendo, portanto, mais alto que esse. Já o seu F2 é, conforme o esperado, significativamente inferior ao de [i], coadunando-se com a tendência centralizadora. A Tabela 3 exibe esses dados: 


\begin{tabular}{|c|c|ccccc|c|}
\hline & \multicolumn{2}{|c}{$[i]$} & \multicolumn{2}{c|}{ [I] } & \multicolumn{3}{c|}{ Resultados de ANOVA } \\
\hline & Média & Des. Pad. & Média & Des. Pad. & F & P>F & $\mathrm{r}^{2}$ \\
\hline F1 & 302.5 & 10.68 & 283.6 & 17.09 & 31.71 & 0.0001 & 0.78 \\
\hline F2 & 2054 & 62.62 & 1877.67 & 160.72 & 39.74 & 0.0001 & 0.79 \\
\hline
\end{tabular}

Tabela 3 - Médias e desvios-padrões de F1 e F2 em Hz para [i] e [I] do Sujeito 2; e resumo dos resultados da análise de variância com valores de F, p e r2

Como o mecanismo de redução da magnitude dos gestos articulatórios só explica a diferença de F2, é preciso, para este sujeito, postular um processo que abaixe F1, situando a vogal pós-tônica acima da tônica correspondente no espaço vocálico. Na FAR esse processo pode ser implementado por um pequeno aumento do grau de constrição. Isso, porém, é apenas uma maneira ad hoc de descrever os dados, nada contribuindo para explicá-los.

Seria possível descrever esse abaixamento de F1de um modo mais natural, que ao menos apontasse para alguma explicação? Outras análises dos dados de Aquino sugerem que sim.

Conforme mostra a Tabela 4, foram encontradas correlações positivas significativas entre os valores de F1 e duração para as vogais pós-tônicas [I] e [๕]. Embora sendo relativamente baixas - provavelmente devido à multiplicidade de fatores que afetam a duração -, essas correlações têm a mesma direção que as observadas na literatura fonética (House, 1961) entre as durações intrínsecas das vogais e as respectivas alturas, a saber: quanto mais baixa é a vogal (ou seja, quanto maior é o seu F1), maior é a duração.

\begin{tabular}{|c|c|c|c|c|}
\hline & $\mathrm{r}$ & $\mathrm{r}^{2}$ & $\mathrm{p}$ & Signifi ficânc in \\
\hline$[\mathrm{I}]$ & 0.51 & 0.26 & 0.004 & $\mathrm{~S}$ \\
\hline$[\mathrm{r}]$ & 0.62 & 0.38 & 0.003 & $\mathrm{~S}$ \\
\hline$[\mathrm{G}]$ & 0.33 & 0.11 & 0.081 & $\mathrm{NS}$ \\
\hline
\end{tabular}

Tabela 4 - Valores do coeficiente de correlação de Pearson (r), r2 e p para F1 e duração das vogais [I], [⿷] e [U] do Sujeito 2

Assim, um modelo dinâmico que incorporasse a altura como descritor vocálico poderia racionalizar esse fato afirmando que, apesar de usar moderadamente a redução, este sujeito tem processos de elevação do [I] e do [⿷] que ajudam a implementar essas vogais com a menor duração característica 
da posição pós-tônica.

A natureza restrita dos dados e o caráter post hoc da última análise tornam impossível, no momento, ir além de apontar a direção aí implícita: tratase de encontrar outros casos em que processos de elevação pareçam atingir conjuntamente as vogais /i/, /a/ e /u/ ou, pelo menos, o /a/ e uma das demais. Se muitos casos desse tipo se acumularem, estará demonstrada a inaptidão da FAR para descrever as generalizações subjacentes a processos vocálicos gradientes do PB. Neste caso, a sua dificuldade com as distinções de altura, recorrentemente encontrada no estudo dos processos categóricos, revelarse-á um problema mais geral, a exigir uma revisão do modelo.

\section{Conclusão: para uma revisão da FAR}

Tudo que se disse acima é muito preliminar para permitir maiores conclusões. Fica, entretanto, claro que a balança pesa a favor da FAR, ainda que exigindo reparos.

Os desacertos apontados na última seção dizem respeito à inadequação de parâmetros específicos, enquanto os acertos apontados na primeira dizem respeito à adequação de princípios gerais. Grande parte da fonologia do PB é gradiente e o único modelo fonológico apto a lidar com isso é a FAR. Se os parâmetros através dos quais ela gera esses gradientes são inadequados, cabe buscar direções para substituí-los.

À guisa de exercício, consideremos a possibilidade de construir um modelo dinâmico que especifique as vogais com os tradicionais parâmetros de altura e posição da língua, ao invés dos graus e lugares de constrição da FAR.

Apesar do ceticismo gerado pelos estudos iniciais de Ladefoged (1971), Lindau (1978) conseguiu, mais tarde, demonstrar que a altura e o recuo da língua têm altas correlações positivas, respectivamente, com F1 e F2-F1, os parâmetros acústicos considerados por aquele autor suficientes para especificar todas as vogais do inglês. Para o PB, os dados de Matta Machado (1993), que incluem as vogais nasais, sugerem algumas complicações: o ponto de elevação máxima da língua é, por exemplo, em [õ] consideravelmente mais baixo que em [⿷â]. Não é impossível, entretanto, que uma normalização adequada da escala com referência ao eixo sagital venha a resolver esse problema, pois [⿷્â] e [õ] se diferenciam claramente quanto ao ponto do eixo sagital em que o máximo do 
eixo vertical é atingido.

Se a empresa parece factível, ela nos confronta, de qualquer forma, com um problema teórico sério: vogais e consoantes devem ser especificadas por parâmetros diferentes, tornando, em princípio, mais difícil expressar interações que não sejam apenas devidas à sobreposição temporal dos gestos. Como descrever, por exemplo, a passagem de [É] a [w], que vem ocorrendo tanto diacrônica como sincronicamente no PB? Em outras palavras, como determinar quando um gesto consonantal se transforma em gesto vocálico? E mais: como exprimir esse processo de maneira contínua, de tal forma que seja possível um contínuo de realizações entre [É] e [w]?

Talvez a solução resida em abordagens como a de Sproat e Fujimura (1993), que reconhecem na produção de consoantes como [É] um componente consonantal e outro vocálico. Uma via importante é investigar se essa solução se aplica também a outros casos em que consoantes se vocalizam (por exemplo,

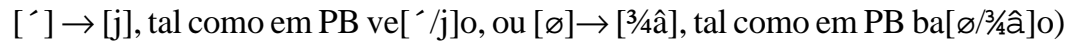
ou provocam ditongações (por exemplo, [s] $\rightarrow$ [ s], tal como em PB rapa[s/ s]).

Mesmo que essas direções se revelem suficientemente viáveis e férteis, a agenda da FAR permanece enorme: o problema fundamental que tem de resolver, para fazer juz à pretensão de ser ao mesmo tempo um modelo fonético e fonológico, é o da redução da dimensionalidade.

A questão a enfrentar é velha: como mapear o discreto no contínuo? Mas o horizonte de resposta delineado pela FAR é novo, por ser o único que afirma a comensurabilidade entre a Fonética e a Fonologia. Quando, no Brasil, tivermos conseguido aproveitar as oportunidades oferecidas pelo PB para limpar, ao menos em parte, o vasto terreno onde essa questão se insere, teremos, finalmente, resgatado o prejuízo de muitos anos de privação do instrumental fonético.

\section{REFERÊNCIAS BIBLIOGRÁFICAS}

Albano, E; P. Barbosa; S. Madureira; A. Gama-Rossi; A. Silva (1998) A interface fonética-fonologia e a interação prosódia-segmentos. Relatório de grupo de trabalho. Estudos Lingüísticos XXVII: Anais do XLV Seminário do Grupo de Estudos Lingüísticos do Estado de São Paulo. São José do Rio Preto: UNESP-IBILCE: 135-143 
AQuino, P. (1997) O papel das vogais reduzidas pós-tônicas na construção de um sistema de síntese concatenativa para o português brasileiro. Dissertação de mestrado. LAFAPE-IEL, UNICAMP.

Browman, C. e L. Goldstein (1985) Dynamic modelling of phonetic structure. In: V. Fromkin (org.) Phonetic Linguistics. Nova Iorque: Academic: $35-53$. (1986) Towards articulatory phnology. Phonology Yearbook, 3: 219-252. (1990a) Tiers in articulatory phonology. In: Kingston \& BeCKMAN (1990):341-376.

(1990b) Gestural specification of dynamically determined articulatory structures. Journal of Phonetics, 18: 299-320.

(1992) Articulatory phonology: an over-view. Phonetica, 49: 155-180.

CÂmara JR., J. M. (1969) Problemas de lingüística descritiva. Petrópolis: Vozes.

(1976) História e estrutura da língua portuguesa. Rio de Janeiro: Padrão. (1977) Para o estudo da fonêmica portuguesa. Rio de Janeiro: Padrão.

Сномsкy, N. е M. Halle (1968) The sound pattern of English. Nova Iorque: Harper e Row.

Clements, G. (1992) Phonological primes: features or gestures? Phonetica, 49:181-193.

Elenius, K.e P. Branderud (1995) (orgs.) Proceedings of the XIIIth Congress of Phonetic Sciences. Estocolmo: Universidade de Estocolmo e Instituto Real de Tecnologia.

Fujimura, O. (1996) The C/D model as a dynamic, non-segmental approach. Relatório Técnico TR-H-184. ATR Human Information Processing Research Laboratories.

House, A. (1961) On vowel duration in English. Journal of the Acoustical Society of America, 33: 1174-8

KoHLER, K. (1995) Phonetics: a language science in its own right? In: ElenIUS \& BRANDERUD, 1: 10-17.

KRÖGER, B. (1993) A gestural production model and its application to reduction in German. Phonetica, 50: 213-233.

Ladefoged, P. (1971) Preliminaries to linguistic phonetics. Chicago: the University of Chicago Press.

Lindau, M. (1978) Vowel features. Language, 54 (3): 541-563.

LindBLom, B. (1963) Spectrographic study of vowel reduction. Journal of the Acoustical Society of America, 35: 1773-1781. 1995. A view of the future of phonetics. In: K.Elenius et al. vol.1.

Matta Machado, M. 1993. Fenômenos de nasalização vocálica em português: estudo cine-radiográfico. Cadernos de Estudos 
Lingüísticos, 25: 113-27.

Онаца, J. 1995. Phonetic explanations of sound patterns: implications for grammars of competence. In: K. Elenius e P. Branderud, vol. 2.

SproAt, R.\&O. Fujimura. 1993. Allophonic variation of English /1/ and its implication for phonetic implementation. Journal of Phonetics 21: 291311.

Stevens, K. 1981. Constraints imposed by the auditory system on the properties used to classify speech sounds; data from phonology, acoustics and psychoacoustics. In: T. Myers, J. Laver e J. Anderson (eds.) The cognitive representaiton of speech. Amasterdam: NorthHolland,.

SousA, E. M. G. 1994. Para a caracterização fonético-acústica da nasalidade no português do Brasil, Dissert de mestrado, LAFAPE-IEL-UNICAMP.

ZsigA, E. 1995. An acoustic and palatographic study of lexical and postlexical. palatalization in American English. In: B. Connell e A. Arvaniti (orgs.) Phonology and PhoneticEvidence:Papers in Laboratory Phonology IV. Cambridge: C.U.P. 1997. Features, gestures, and Igbo vowel assimilation: an approach to the phonology/phonetics mapping. Language 73 (2):227-274 